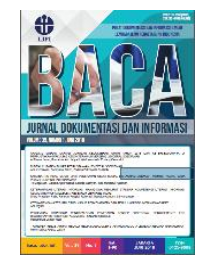

\title{
ANALISIS TINGKAT KEPUASAN PEMUSTAKA TERHADAP LAYANAN DI PERPUSTAKAAN BALAI ARKEOLOGI DAERAH ISTIMEWA YOGYAKARTA DENGAN METODE LIBQUAL ${ }^{+T M}$
}

\author{
Bayu Indra Saputro ${ }^{1 *}$; Puspitaningrum Timur Utami ${ }^{2}$ \\ $1 \& 2$ Balai Arkeologi Daerah Istimewa Yogyakarta \\ *Korespondensi: bayu.library@gmail.com
}

Diajukan: 14-06-2019; Direview: 15-08-2019; Diterima: 08-09-2019; Direvisi: 01-10-2020

\begin{abstract}
The purpose of this study was to determine the satisfaction of users of the quality of service in the Balai Arkeologi Daerah Istimewa Yogyakarta library using the LibQUAL ${ }^{+\mathrm{TM}}$, in this method there are four indicators namely affect service, library as place, personal control, and information access. The research method used in this study is to use quantitative methods. The population in this study is the visitors who come to the library from April to December 2018. The sample used in this study amounted to 50 respondents. Gap analysis shows that the overall dimensions of LibQUAL ${ }^{+\mathrm{TM}}$ are negative. So there is a need for corrective actions to meet the user's expectations. By using importance-performance analysis, it was found that subvariable personal control on modern equipment items (items 20) had a gap of -0.76 . The user assumed that the photocopy machine facilities and infrastructure were needed by the user, but in fact the photo copy service was not provided by the library. Whereas the value of the User Satisfaction Index at the Balai Arkeologi Daerah Istimewa Yogyakarta library shows a number of $87.43 \%$, which indicates the user satisfaction index is satisfied with the performance of library services.
\end{abstract}

\begin{abstract}
ABSTRAK
Tujuan penelitian ini adalah mengetahui kepuasan pemustaka terhadap kualitas layanan di perpustakaan Balai Arkeologi Daerah Istimewa Yogyakarta dengan menggunakan metode LibQUAL ${ }^{+\mathrm{TM}}$. Dalam metode ini terdapat empat indicator, yaitu service affect, library as place, personal control, dan information acces. Metode penelitian yang digunakan dalam penelitian ini adalah metode kuantitatif. Populasi dalam penelitian ini adalah pemustaka yang datang ke perpustakaan dari bulan April s.d. Desember 2018. Sampel yang digunakan dalam penelitian ini berjumlah 50 responden. Melalui analisis gap diketahui bahwa keseluruhan dimensi LibQUAL ${ }^{+T M}$ tersebut bernilai negatif. Sehingga perlu adanya tindakan perbaikan agar memenuhi harapan pemustaka. Dengan menggunakan importance-performance analysis didapatkan bahwa suubvariabel personal control pada item modern equipment (item 20) memiliki nilai gap $-0,76$. Pemustaka menganggap bahwa sarana dan prasarana mesin fotokopi sangat diperlukan oleh pemustaka, tetapi pada kenyataannya layanan fotokopi tidak disediakan oleh perpustakaan. Sementara itu, nilai Indeks Kepuasan Pengguna di Perpustakaan Balai Arkeologi Daerah Istimewa Yogyakarta menunjukkan angka 87,43\%, yang menunjukkan bahwa indeks kepuasan pemustaka merasa puas dengan kinerja layanan perpustakaan.
\end{abstract}

Keywords: User satisfaction; Library services; Special library; LibQUAL

\section{PENDAHULUAN}

Keberadaan perpustakaan muncul karena kebutuhan pemustaka yang menginginkan tersedianya bank data yang dapat menyimpan, mengolah, dan melayangkan kembali data kepada pemustaka. Adanya kebutuhan tersebut, Balai Arkeologi di bawah Pusat Penelitian Arkeologi Nasional mendirikan perpustakaan dengan tujuan manajemen data penelitian, jurnal ilmiah, dan buku tentang arkeologi yang diterbitkan oleh setiap instansi, atau buku referensi yang mendukung penelitian arkeologi. Perpustakaan Balai Arkeologi awalnya perpustakaan 
tertutup yang melayani pemustaka internal saja, tetapi seiring dengan perkembangan organisasi, perpustakaan ini dapat diakses oleh pemustaka dari luar instansi (Saputro, 2012).

Perpustakaan Balai Arkeologi Daerah Istimewa Yogyakarta (Balai Arkeologi Yogyakarta) meningkatkan layanan informasi dengan cara menyediakan: katalog perpustakaan online dengan aplikasi SLIMS, layanan jurnal Berkala Arkeologi, dan repositori Kemdikbud. Selain itu, disediakan ruangan ber-AC dan juga penerangan yang dapat membuat pengujung lebih nyaman untuk membaca. Agar layanan dapat dimanfaatkan secara maksimal oleh pemustaka, perpustakaan meningkatkan kemampuan komunikasi pustakawan dalam melayani pemustaka. Komunikasi menjadi penting karena merupakan hal yang menghubungkan antara pemustaka dan pustakawan dalam transfer informasi sehingga kebutuhan pengguna dapat terpenuhi. Kemudian, faktor fasilitas yang mudah diakses dan kejelasan prosedur merupakan faktor yang penting dalam penilaian kualitas layananan perpustakaan.

Evaluasi Perpustakaan Balai Arkeologi Yogyakarta belum pernah dilakukan, khususnya pada desain ruang perpustakaan dan ruang perpustakaan, fasilitas komputer, jam layanan, fasilitas internet (WiFi), buku referensi arkeologi, fasilitas terminal listrik, meja dan kursi. Sebagai bahan evaluasi kualitas layanan suatu perpustakaan dalam perspektif pemustaka, salah satu metode yang dapat digunakan adalah LibQUAL ${ }^{+\mathrm{TM}}$ (Library Quality). LibQUAL bertujuan untuk mengetahui kebutuhan pemustaka terhadap layanan perpustakaan. Menurut Nurkertamanda \& Wirawan (2009) LibQUAL $^{+\mathrm{TM}}$ merupakan alat atau metode yang digunakan perpustakaan untuk mengumpulkan, mencari, memahami, dan menanggapi opini pengguna terhadap kualitas layanan yang diberikan oleh perpustakaan. Penelitian ini membahas tentang perspektif pemustaka tentang pelayanan di Perpustakaan Balai Arkeologi Yogyakarta dan pengukuran terhadap kualitas layanan perpustakaan. Penelitian ini dinilai sangat penting karena untuk mengetahui tingkat layanan perpustakaan berdasarkan perspektif pemustaka, serta mengetahui dimensi kualitas layanan perpustakaan.

\section{TINJAUAN PUSTAKA}

\subsection{Penelitian Terdahulu}

Fatmawati (2012) telah mengukur evaluasi kualitas layanan perpustakaan Fakultas Ekonomika dan Bisnis UNDIP berdasarkan harapan dan persepsi pemustaka dengan Metode LibQUAL $^{+\mathrm{TM}}$. Berdasarkan analisis Adequacy Gap $(A G)$, dimensi yang memenuhi harapan dan persepsi pemustaka adalah dimensi Information Access (IA) sebesar 5,160. Sementara itu, berdasarkan dari hasil analisis Superiority Gap (SG), dimensi Personal Control (PC) adalah dimensi yang belum memenuhi harapan dan persepsi pesmustaka sebesar -15,889.

Aliza (2017) menggunakan Metode LibQUAL ${ }^{+\mathrm{TM}}$ untuk mengukur kualitas layanan di UPT Perpustakaan Universitas Negeri Padang (UNP), dengan hasil: (1) kemampuan dan sikap pustakawan dalam melayani (service affect-SA) dengan nilai Indeks Kepuasan Pemustaka (IKP) $12 \%$; (2) dimensi fasilitas dan suasana ruang perpustakaan (library as place-LP) dengan nilai IKP 13,80\%; (3) petunjuk dan sarana akses (personal control-PC) dengan nilai IKP 14,66\%; (4) akses informasi (information access-IA) dengan nilai IKP 13,15\%. Nilai indeks kepuasan pemustaka secara keseluruhan dari dimensi LibQUAL ${ }^{+\mathrm{TM}}$ yaitu $13,35 \%$, berarti 5 dari responden menyatakan puas terhadap kinerja layanan di Perpustakaan, sedangkan 35 dari 40 responden mengatakan tidak puas dengan kinerja layanan di UPT Perpustakaan UNP, berarti kualitas layanan di UPT Perpustakaan UNP belum memenuhi skala maksimum IKP.

Penelitian lainnya tentang persepsi pemustaka terhadap kualitas layanan Window Of The World (WoW) Perpustakaan UGM berdasarkan model LibQUAL ${ }^{+\mathrm{TM}}$ yang dilakukan oleh 
Oktaviela (2016), hasilnya menunjukkan bahwa nilai rata-rata persepsi pemustaka sebesar 3.09 yang berarti dikategorikan baik. Hasil analisis persepsi pemustaka dari keempat dimensi yang memiliki nilai rata-rata terendah dari tiap dimensi tersebut, yaitu: (1) dimensi Service Affect-SA yaitu pada indikator empathy, pada pernyataan pustakawan memberikan perhatian yang sungguh-sungguh kepada pemustaka; (2) dimensi Library As Place-LP, yaitu pada indikator tangibles, pada pernyataan ketersediaan buku bacaan di layanan WoW mencukupi dengan kebutuhan pemustaka; (3) dimensi Personal Control-PC, yaitu pada indikator convenience, pada pernyataan petunjuk yang dapat memudahkan pemustaka memanfaatkan fasilitas dan koleksi di layanan WoW; (4) dimensi Information Access-IA, yaitu pada indikator conten/scope, pada pernyataan dalam hal ketersediaan buku dalam bentuk budaya Indonesia dan berbagai negara lain sudah mencukupi yang pemustaka butuhkan.

\subsection{Evaluasi Layanan}

Evaluasi diartikan sebagai salah satu proses penilaian terhadap salah satu kegiatan supaya bisa dilihat sudah sesuai dengan harapan atau belum. Evaluasi dapat juga diartikan sebagai proses pengukuran akan sukses atau tidaknya suatu strategi yang digunakan dalam upaya mencapai tujuan institusi, khususnya perpustakaan (Prasetyo, 2016). Data yang diperoleh dari hasil pengukuran evaluasi tersebut akan digunakan sebagai analisis untuk pengambilan keputusan guna tercipta hasil yang baik dengan tahapan yang harus dilalui, yakni menentukan permasalahan, pendekatan permasalahan, menyusun desain penelitian, melakukan penelitian lapangan untuk mengumpulkan data, menganalisis data, dan menyampaikan hasil penelitian.

Menurut Suwarno (2016: 99) pelayanan adalah tindakan seseorang atau organisasi untuk memberikan kepuasan kepada pelanggan. Kualitas layanan merupakan bentuk penilaian dari seorang pemustaka terhadap layanan yang diterima,apakah sesuai dengan harapannya (Aliza \& Ardoni (2017). Menurut Fatmawati (2013), kualitas layanan perpustakaan lebih menekankan pada aspek kepuasan dengan fokus utamanya, yaitu keperluan atau kebutuhan pemustaka (users utility). Kualitas merupakan faktor penting dalam meraih kepuasan pemustaka dalam menunjang keberhasilan layanan jasa perpustakaan sehingga perlu dilakukan pengontrolan kualitas untuk menjaga mutu layanan, salah satu cara untuk pengontrolan kualitas tersebut adalah dengan teknik evaluasi.

\subsection{LibQUAL $^{+\mathrm{TM}}$}

Sejarah kelahiran LibQUAL ${ }^{+\mathrm{TM}}$ muncul pada tahun 1999, pelopornya adalah Colleen Cook (Executive Associate Dean: Wright Profesor Ilmu Perpustakaan) dan Fred Heath (Dean of libraries: pemilik Sterling Evans Chair) dari Texas A\&M University (TAMU). Cook dan Heath selama beberapa tahun telah menyadari bahwa penggunaan berbagai variabel "input", seperti jumlah koleksi atau serial, masih terbatas sebagai ukuran kualitas layanan perpustakaan. Pada tahun 1995, 1997 dan 1999, Cook dan Heath mengumpulkan persepsi kualitas layanan dengan sampel pemustaka di perpustakaan Texas A\&M University (TAMU), dengan menggunakan model SERVQUAL yang dikembangkan oleh Profesor di Texas A\&M University (TAMU), yaitu Zeithaml, Parasuranam, dan Berry pada tahun 1980. Prinsip LibQUAL $^{+\mathrm{TM}}$ adalah hanya pemustaka yang berhak untuk menilai kualitas layanan, sementara seluruh penilaian lainnya sebenarnya tidak relevan (Fatmawati, 2013).

Menurut Achmad, dkk (2012), LibQUAL ${ }^{+\mathrm{TM}}$ bersumber dari konsep SERVQUAL yang digunakan untuk mengukur kualitas layanan di sektor usaha berlaba. Fatmawati (2012) 
menyebutkan LibQUAL ${ }^{+\mathrm{TM}}$ sebagai metode pengukuran kualitas layanan perpustakaan berdasarkan persepsi dan harapan pemustaka dapat menjadi instrumen yang luwes dan menjadi salah satu sarana pustakawan untuk menjalin komunikasi dengan pemustaka. Metode LibQUAL $^{+\mathrm{TM}}$ memiliki empat dimensi, yaitu: (1) kemampuan pustakawan dalam melayani; (2) fasilitas dan suasana ruang perpustakaan; (3) petunjuk dan sarana akses; (4) akses informasi dalam penelusuran bahan pustaka. Penjelasan terhadap pengukuran dimensi LibQUAL ${ }^{+\mathrm{TM}}$, tersebut sebagai berikut.

1) Kemampuan dan sikap pustakawan dalam melayani (service affect-SA), yaitu kemampuan dan sikap pustakawan dalam melayani pemustaka. Kualitas layanan perpustakaan akan menjadi baik apabila pustakawan dapat berkomunikasi dengan pemustaka. Dimensi dari Service Affect yaitu: (a) empati/ kepedulian (empathy) : threating customer as individuals; (b) ketanggapan (responsiveness) : being willing to help; (c) jaminan/ kepastian (assurance) : inspiring truth and confidence; (d) reliabilitas/ keandalan (reliability): delivering on promise.

2) Fasilitas dan suasana lingkungan perpustakaan (Library as Place-LP), yaitu perpustakaan dianggap mempunyai kemampuan untuk menyediakan fasilitas fisik (physical facilities) bagi pemustaka, baik ruang baca yang nyaman, sarana dan prasarana (equipment), maupun ketersediaan sarana peralatan komunikasi dan petugas (personnel and communication material)..

3) Petunjuk dan sarana akses (personnal control-PC), yaitu sebuah konsep yang menjadikan pemustaka dapat melakukan penelusuran informasi yang diinginkan secara mandiri. Aspek dari personnal control mencakup: kemudahan akses (ease of navigation); kenyamanan individu pemustaka (convenience); peralatan yang modern (modern equipment); dan kepercayaan diri (self reliance).

4) Akses informasi (information access-IA), yaitu menyangkut ketersediaan bahan koleksi perpustakaan yang memadai, bimbingan pustakawan, maupun tingkat kecepatan waktu akses informasi di perpustakaan. Dimensi akses informasi mencakup: isi atau ruang lingkup (content/scope) dan kecepatan waktu akses (timeliness).

Menurut Woodward (2009), metode LibQUAL ${ }^{+\mathrm{TM}}$ dapat digunakan pustakawan untuk mengetahui kebutuhan pemustaka dan memperbaiki apa yang masih kurang dari persepsi pemustaka. LibQUAL ${ }^{+\mathrm{TM}}$ dapat mengidentifikasi apa yang menjadi kekuatan dan kelemahan perpustakaan dilihat dari perspektif pemustakanya. Cook; Heath; \& Thompson (2003) dan Budd (2005) mengatakan bahwa metode LibQUAL ${ }^{+\mathrm{TM}}$ dapat digunakan untuk mendengarkan pemustaka.

\section{METODE}

\subsection{Populasi dan Sampel}

Jenis penelitian ini adalah penelitian survei dengan metode penelitian kuantitatif. Data diperoleh melalui kuesioner penelitian. Menurut Sugiyono (2009) kuisioner merupakan teknik pengumpulan data yang dilakukan dengan cara memberikan seperangkat pernyataan tertulis kepada responden untuk dijawab. Penentuan sampel menggunakan teknik simple random sampling. Peneliti menggunakan angket dari Prasetyo (2016) yang sudah dilakukan uji validitas dan reabilitas (Tabel 2). Kuesioner disebarkan kepada 50 responden yang datang ke perpustakaan Balai Arkeologi Yogyakarta dalam rentang waktu bulan April s.d Desember 2018 (Tabel 1). 
Tabel 1. Komposisi Responden Berdasarkan Jenis Kelamin

\begin{tabular}{|c|l|c|}
\hline No. & Jenis Kelamin & Jumlah \\
\hline 1 & Laki-laki & 29 \\
\hline 2 & Perempuan & 21 \\
\hline 3 & Tidak Menjawab & 0 \\
\hline
\end{tabular}

\subsection{Variabel Penelitian}

Penelitian ini menggunakan satu variabel, yaitu kualitas layanan perpustakaan (Tabel 2).

Tabel 2. Variabel, Subvariabel, Pertanyaan, dan Indikator

\begin{tabular}{|c|c|c|c|c|}
\hline Variabel & Sub-Variabel & $\begin{array}{l}\text { No } \\
\text { Item }\end{array}$ & $\begin{array}{c}\text { Item } \\
\text { (Pertanyaan) }\end{array}$ & Dimensi \\
\hline \multirow{17}{*}{$\begin{array}{l}\text { Kualitas } \\
\text { layanan } \\
\text { perpustakaan }\end{array}$} & \multirow{7}{*}{$\begin{array}{l}\text { Kemampuan dan } \\
\text { sikap } \\
\text { pustakawan } \\
\text { dalam melayani) }\end{array}$} & 1. & $\begin{array}{l}\text { Pustakawan memahami kebutuhan saya di } \\
\text { perpustakaan }\end{array}$ & Empathy \\
\hline & & 2. & $\begin{array}{l}\text { Kesediaan pustakawan untuk membantu } \\
\text { kesulitan saya di perpustakaan }\end{array}$ & \multirow[b]{2}{*}{ Responsiveness } \\
\hline & & 3. & $\begin{array}{l}\text { Pustakawan selalu tanggap memberikan } \\
\text { bantuan dalam mencari informasi yang saya } \\
\text { perlukan }\end{array}$ & \\
\hline & & & $\begin{array}{l}\text { Keramahan pustakawan dalam memberikan } \\
\text { layanan }\end{array}$ & \multirow{2}{*}{ Assurance } \\
\hline & & 5. & $\begin{array}{l}\text { Kesopanan pustakawan dalam memberikan } \\
\text { layanan }\end{array}$ & \\
\hline & & 6. & $\begin{array}{l}\text { Waktu layanan sesuai dengan jam buka/ } \\
\text { tutup perpustakaan }\end{array}$ & \multirow[b]{2}{*}{ Reliability } \\
\hline & & 7. & $\begin{array}{l}\text { Kemampuan pustakawan dalam menjawab } \\
\text { pertanyaan yang saya ajukan }\end{array}$ & \\
\hline & \multirow{8}{*}{$\begin{array}{l}\text { Library as place } \\
\text { (fasilitas dan } \\
\text { suasana } \\
\text { perpustakaan) }\end{array}$} & 8. & $\begin{array}{l}\text { Ketersediaan buku di perpustakaan } \\
\text { membantu saya dalam menyelesaikan tugas } \\
\text { kuliah }\end{array}$ & \multirow[t]{2}{*}{ Tangibles } \\
\hline & & 9. & $\begin{array}{l}\text { Kondisi gedung maupun peralatan dan } \\
\text { perlengkapan yang baik }\end{array}$ & \\
\hline & & 10. & $\begin{array}{l}\text { Ketenangan ruangan perpustakaan untuk } \\
\text { belajar }\end{array}$ & \multirow[b]{2}{*}{ Utilitarian Space } \\
\hline & & 11. & $\begin{array}{l}\text { Adanya desain ruangan perpustakaan } \\
\text { sebagai tempat diskusi yang menarik minat } \\
\text { pengguna }\end{array}$ & \\
\hline & & 12. & $\begin{array}{l}\text { Perpustakaan dapat memunculkan berbagai } \\
\text { inspirasi untuk membaca dan belajar. }\end{array}$ & \multirow{2}{*}{- Symbol } \\
\hline & & 13. & $\begin{array}{l}\text { Perpustakaan terbuka untuk umum dalam } \\
\text { belajar/ berdiskusi bersama }\end{array}$ & \\
\hline & & 14. & $\begin{array}{l}\text { Ketersediaan ruang perpustakaan yang } \\
\text { nyaman untuk belajar }\end{array}$ & \multirow{4}{*}{ Easy of navigation } \\
\hline & & 15 . & $\begin{array}{l}\text { Kondisi perpustakaan yang selalu bersih } \\
\text { dan dijaga dengan baik sehingga kondusif } \\
\text { untuk belajar }\end{array}$ & \\
\hline & \multirow{2}{*}{$\begin{array}{l}\text { Personal control } \\
\text { (petunjuk dan } \\
\text { sarana akses) }\end{array}$} & 16. & $\begin{array}{l}\text { Kemudahan saya dalam melakukan } \\
\text { penelusuran informasi di perpustakaan }\end{array}$ & \\
\hline & & 17. & $\begin{array}{l}\text { Penataan koleksi perpustakaan } \\
\text { memudahkan saya dalam proses temu }\end{array}$ & \\
\hline
\end{tabular}




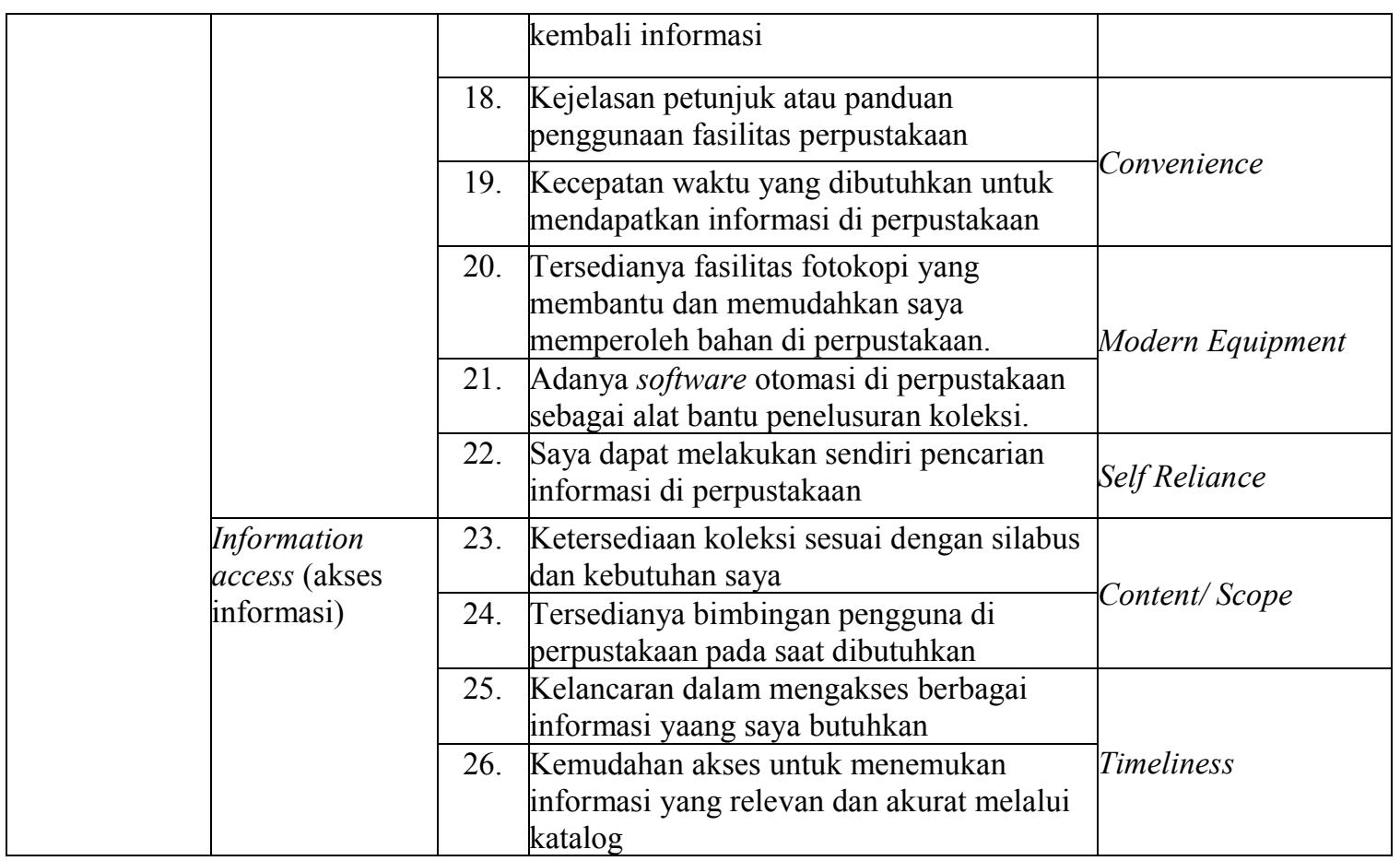

Sumber: Daftar Instrumen Penelitian (Prasetyo 2016)

\subsection{Pengukuran Data}

Penelitian ini menggunakan metode pengukuran data dengan skala likert. Skala likert digunakan untuk mengukur opini atau persepsi responden berdasarkan tingkat persetujuan atau ketidaksetujuan. Dalam skala likert ini, setiap jawaban setiap item intrumen diberi skor dengan skala 1-5. Adapun skala untuk pertanyaan importance 'tingkat kepentingan' sebagai berikut.

$\begin{array}{lll}\text { Sangat Tidak Penting } & \text { (STP) } & \text { dengan skala 1 } \\ \text { Tidak Penting } & \text { (TP) } & \text { dengan skala 2 } \\ \text { Kurang Penting } & \text { (KP) } & \text { dengan skala 3 } \\ \text { Penting } & \text { (P) } & \text { dengan skala 4 } \\ \text { Sangat Penting } & \text { (SP) } & \text { dengan skala 5 }\end{array}$

Sementara itu, skala untuk pertanyaan performance 'tingkat kinerja' sebagai berikut.

$\begin{array}{lll}\text { Sangat Tidak Baik } & \text { (STB) } & \text { dengan skala 1 } \\ \text { Tidak Baik } & \text { (TB) } & \text { dengan skala 2 } \\ \text { Kurang Baik } & \text { (KB) } & \text { dengan skala 3 } \\ \text { Baik } & \text { (B) } & \text { dengan skala 4 } \\ \text { Sangat Baik } & \text { (SB) } & \text { dengan skala 5 }\end{array}$

\subsection{Uji Validitas dan Reabilitas}

Untuk melakukan uji validitas dan uji reliabilitas, digunakan softtware SPSS 20.0. Berdasarkan nilai $r_{\text {tabel }}$ pada $\mathrm{n}=50(\mathrm{df}=$ table 48$)$ dengan taraf kesalahan 5\% (taraf kepercayaan 95\%) diperoleh angka 0,284 dan jika dibandingkan dengan nilai $r_{\text {hitung }}$ untuk tiap hitung pertanyaan kuesioner pada bagian persepsi/ tingkat kinerja dan pada bagian harapan/ tingkat kepentingan, didapat nilai $r_{\text {hiung }}>$ hitung nilai $r_{\text {tabel }}$ sehingga setiap item pertanyaan tabel tersebut valid (Sugiyono, 2009). Hasil uji validitas penelitian dapat dilihat pada Tabel 3. 
Tabel 3. Hasil Uji Validtas Importance dan Performance

\begin{tabular}{|c|c|c|c|c|}
\hline \multirow{2}{*}{ Item } & \multicolumn{2}{|c|}{ Nilai $r_{\text {hitung }}$} & \multirow{2}{*}{ Nilai $r_{\text {tabel }}$} & \multirow{2}{*}{ Kesimpulan } \\
\cline { 2 - 3 } & Performance & Importance & & \\
\hline 1 & 0,792 & 0,564 & 0,284 & Valid \\
\hline 2 & 0,861 & 0,807 & 0,284 & Valid \\
\hline 3 & 0,655 & 0,822 & 0,284 & Valid \\
\hline 4 & 0,883 & 0,817 & 0,284 & Valid \\
\hline 5 & 0,883 & 0,911 & 0,284 & Valid \\
\hline 6 & 0,865 & 0,857 & 0,284 & Valid \\
\hline 7 & 0,88 & 0,615 & 0,284 & Valid \\
\hline 8 & 0,83 & 0,855 & 0,284 & Valid \\
\hline 9 & 0,717 & 0,69 & 0,284 & Valid \\
\hline 10 & 0,731 & 0,745 & 0,284 & Valid \\
\hline 11 & 0,711 & 0,775 & 0,284 & Valid \\
\hline 12 & 0,839 & 0,807 & 0,284 & Valid \\
\hline 13 & 0,749 & 0,766 & 0,284 & Valid \\
\hline 14 & 0,789 & 0,832 & 0,284 & Valid \\
\hline 15 & 0,462 & 0,826 & 0,284 & Valid \\
\hline 16 & 0,809 & 0,903 & 0,284 & Valid \\
\hline 17 & 0,809 & 0,588 & 0,284 & Valid \\
\hline 18 & 0,733 & 0,846 & 0,284 & Valid \\
\hline 19 & 0,434 & 0,732 & 0,284 & Valid \\
\hline 20 & 0,464 & 0,687 & 0,284 & Valid \\
\hline 21 & 0,545 & 0,716 & 0,284 & Valid \\
\hline 22 & 0,609 & 0,665 & 0,284 & Valid \\
\hline 23 & 0,678 & 0,854 & 0,284 & Valid \\
\hline 24 & 0,59 & 0,821 & 0,284 & Valid \\
\hline 25 & 0,859 & 0,802 & 0,284 & Valid \\
\hline 26 & 0,716 & 0,759 & 0,284 & Valid \\
\hline
\end{tabular}

Berdasarkan nilai $r_{\text {tabel }}$ pada $\mathrm{n}=50(\mathrm{df}=$ table 48$)$ dengan taraf kesalahan $5 \%$ (taraf kepercayaan 95\%) diperoleh angka 0,284 dan jika dibandingkan dengan Alpha Cronbach's, diperoleh bahwa nilai Apha Cronbach's $>$ nilai $r_{\text {tabel }}$ sehingga kuesioner dinyatakan reliabel (lihat Tabel 4).

Tabel 4. Hasil Uji Reliabel Importance dan Performance

\begin{tabular}{|l|c|c|}
\hline \multicolumn{1}{|c|}{ Item Penilaian } & Performance & Importance \\
\hline $\mathrm{N}$ item & 26 & 26 \\
\hline Nilai Alpha Cronbach's & 0,958 & 0,969 \\
\hline Nilai rtabel & 0,284 & 0,284 \\
\hline Kesimpulan & Reliabel & Reliabel \\
\hline
\end{tabular}




\subsection{Teknik Analisis Data}

Selain menggunakan analisis nilai $\mathrm{SG}$ dan $\mathrm{AG}$, metode $\mathrm{LibQUAL}{ }^{+\mathrm{TM}}$ juga bisa digunakan untuk analisis Importance Performance Analysis (IPA). Teknik analisis data ini merupakan teknik statistik yang bercorak deskriptif. Dalam teknik analisis IPA, menurut Tjiptono (2012) responden diminta menilai tingkat kepentingan (importance) dan tingkat kinerja (performance) pada tiap pertanyaan dalam kuesioner. Nilai rata-rata tingkat kepentingan dan kinerja akan dianalisis di importance-performance matrix. Matriks ini sangat bermanfaat sebagai pedoman dalam melakukan perbaikan kinerja yang dapat berdampak besar pada kepuasan pelanggan.

Penerapan IPA di perpustakaan dapat memudahkan pustakawan dalam mengkaji kualitas dan kinerja layanan perpustakaan. Hasil penerapan model ini menampilkan analisis usulan perbaikan kinerja perpustakaan secara komprehensif dan mengidentifikasi prioritas indikator apa saja dalam dimensi LibQUAL ${ }^{+\mathrm{TM}}$ yang terbagi dalam keempat kuadran. Dalam model IPA, analisis data terdiri dari dua komponen yaitu:

1. Analisis kesenjangan ( $\mathrm{gap}$ ) merupakan analisis yang digunakan untuk melihat kesenjangan antara kinerja layanan perpustakaan dan harapan pemustaka terhadap layanan yang telah diberikan. Analisis gap (P-I) dilakukan dengan tahapan sebagai berikut.

a) Menghitung rata-rata penilaian penilaian tingkat kepentingan dan tingkat kinerja untuk setiap indikator dengan rumus:

$$
X i=\frac{\Sigma \mathrm{Xi}}{\mathrm{n}} \quad Y i=\frac{\Sigma \mathrm{Yi}}{\mathrm{n}}
$$

Keterangan:

Xi: Skor rata-rata tingkat kinerja layanan perpustakaan

Yi: Skor rata-rata tingkat kepentingan terhadap layanan.

$\mathrm{n}$ : Jumlah responden

b) Menghitung nilai kesenjangan (gap) dengan rumus:

$\mathrm{G}=\mathrm{P}($ performance $)-\mathrm{I}($ importance $)$.

Apabila mengukur kepuasan pemustaka menggunakan IPA, kata harapan pemustaka dapat diganti dengan tingkat kepentingan (importance), yang artinya tingkat kepentingan menurut pemustaka. Sementara itu, persepsi pemustaka bisa diganti dengan tingkat kinerja (performance) yang telah diberikan oleh perpustakaan. Kesenjangan (gap) bernilai negatif menunjukkan bahwa harapan konsumen tidak terpenuhi. Semakin besar kesenjangan, semakin lebar jurang pemisah antara keinginan konsumen dan sesuatu yang mereka peroleh sebenarnya (Wijaya, 2011).

c) Indeks kepuasan pengguna (IKP) merupakan analisis kuantitatif berupa persentase pengguna yang senang dalam suatu survei kepuasan pengguna. IKP diperlukan untuk mengetahui tingkat kepuasan pengguna secara menyeluruh dengan memperhatikan tingkat kepentingan dari atribut produk atau jasa. Pada penelitian ini, nilai skor tertinggi pada skala pengukuran yang dipakai adalah 5, dengan rumus IKP sebagai berikut.

$$
\mathrm{IKP}=\frac{\mathrm{T}}{5 \mathrm{Y}} \times 100 \%
$$


Keterangan :

IKP : indeks kepuasan pengguna

$\mathrm{T}$ : jumlah nilai rata-rata pada kolom rata-rata skor kepentingan (I)

Y : jumlah hasil kali antara I dengan P pada kolom skor (S)

Perhitungan keseluruhan IKP, menurut Bhote (1996) nilai rata-rata tingkat kepentingan (I) dijumlahkan sehingga diperoleh $\mathrm{Y}$. $\mathrm{P}$ adalah jumlah nilai rata-rata kinerja sesungguhnya. Hasil kali I dengan $\mathrm{P}$ dijumlahkan dan diperoleh $\mathrm{T}$. Nilai maksimum IKP adalah 100\%, dengan ketentuan nilai IKP 50\% atau lebih rendah menandakan kinerja layanan yang kurang baik di mata pengguna. Nilai IKP $80 \%$ atau lebih tinggi mengindikasikan pengguna merasa puas terhadap kinerja pelayanan.

Analisis kuadran ini digunakan untuk mengetahui respon pemustaka terhadap layanan yang diberikan perpustakaan berdasarkan tingkat kepentingan dan kinerja dari pustakawannya. Menurut Supranto (1997) diagram kartesius merupakan suatu bangun yang dibagi atas empat bagian yang dibatasi oleh dua buah garis yang berpotongan tegak lurus pada titik-titik $(\overline{\bar{x}}, \overline{\bar{y}})$. Dengan keterangan, $\overline{\bar{x}}$ rata-rata tingkat kinerja (performance), sedangkan $\overline{\bar{y}}$ rata-rata skor kepentingan (importance). Pengolahan diagram kartesius menggunakan software SPSS 20.0. Interpretasi dari grid tingkat kinerja-tingkat kepentingan dapat diilustrasikan sebagai berikut.

I. Menunjukkan faktor atau atribut yang dianggap mempengaruhi kepuasan pelanggan dan dianggap sangat penting, tetapi perpustakaan belum melaksanakannya sesuai keinginan pelanggan. Akibatnya, pelanggan kecewa /tidak puas.

II. Menunjukkan unsur jasa pokok yang telah berhasil dilaksanakan perusahaan dan wajib dipertahankannya karena dinilai sangat penting dan sangat memuaskan.

III. Menunjukkan beberapa faktor yang kurang penting pengaruhnya bagi pelanggan, pelaksanaannya oleh perpustakaan biasa-biasa saja. Dianggap kurang penting dan kurang memuaskan.

IV. Menunjukkan faktor yang mempengaruhi pelanggan kurang penting, tetapi pelaksanaannya berlebihan. Dianggap kurang penting, tetapi sangat memuaskan (Prihati, 2011). 
Extremely important

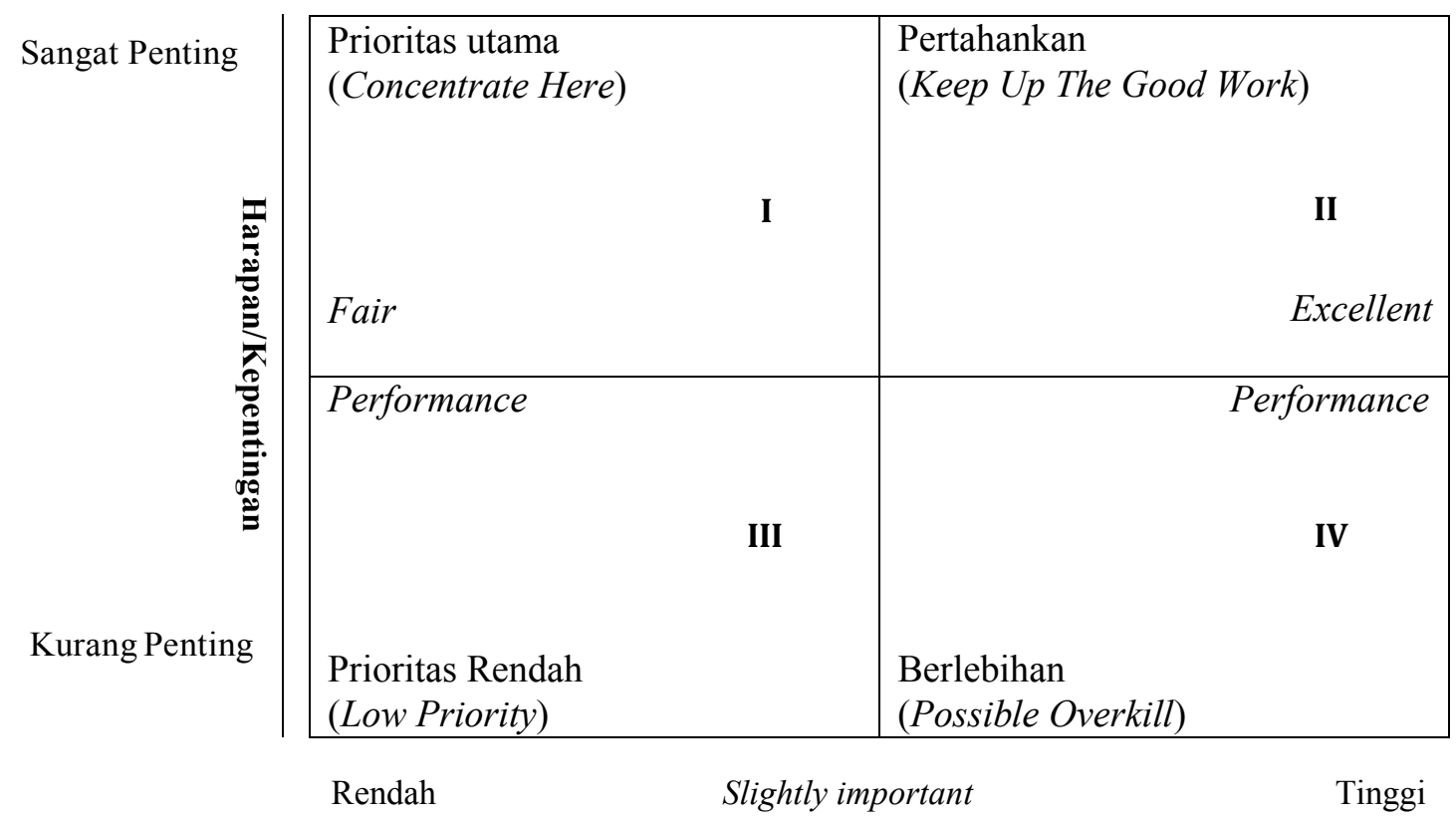

Gambar 1. Diagram importance dan performance matrix

(Sumber: Rangkuti dalam Fatmawati, 2012)

\section{HASIL DAN PEMBAHASAN}

\subsection{Analisis Tingkat Kepuasan}

Perbedaan antara persepsi/kinerja dengan harapan/kepentingan membentuk sebuah gap yang digunakan untuk mengukur tingkat kualitas pelayanan. Gap yang bernilai negatif berarti pelayanan yang diterima sangatlah buruk sehingga tidak ada pelanggan yang merasa puas. Gap yang bernilai positif menunjukkan bahwa pelayanan yang diberikan sangatlah baik dan konsumen merasa puas (Daniel \& Berinyuy, 2010). Tabel 5 menunjukkan tabulasi data total nilai dimensi LibQUAL ${ }^{+\mathrm{TM}}$ yang diperoleh dari kuesioner pemustaka.

Tabel 5. Tabualsi Data Total Nilai Dimensi LibQUAL ${ }^{+\mathrm{TM}}$

\begin{tabular}{|l|c|c|}
\hline \multicolumn{1}{|c|}{ Dimensi } & Importance (I) & Performance (P) \\
\hline Service Affect & & \\
\hline Empathy/ Kepedulian 1 & 231 & 228 \\
\hline Responsivenes 2 & 237 & 226 \\
\hline Responsivenes 3 & 233 & 220 \\
\hline Assurance/ Jaminan 4 & 232 & 226 \\
\hline Assurance/ Jaminan 5 & 233 & 226 \\
\hline Reliabilitas/ keandalan 6 & 231 & 223 \\
\hline Reliabilitas/ keandalan 7 & 225 & 222 \\
\hline Library As Place & & \\
\hline Tangibles/ bukti fisik 8 & 237 & 221 \\
\hline Tangibles/ bukti fisik 9 & 230 & 213 \\
\hline Utilitarian Space 10 & 232 & 221 \\
\hline
\end{tabular}




\begin{tabular}{|l|c|c|}
\hline Utilitarian Space 11 & 229 & 206 \\
\hline Symbol 12 & 231 & 218 \\
\hline Symbol 13 & 229 & 219 \\
\hline Refuge/ Tempat nyaman 14 & 231 & 217 \\
\hline Refuge/ Tempat nyaman 15 & 235 & 222 \\
\hline Personal Control & & \\
\hline Easy of navigation 16 & 234 & 227 \\
\hline Easy of navigation 17 & 231 & 227 \\
\hline Convenience 18 & 229 & 210 \\
\hline Convenience 19 & 228 & 208 \\
\hline Modern Equipment 20 & 225 & 187 \\
\hline Modern Equipment 21 & 237 & 223 \\
\hline Self Reliance 22 & 235 & 224 \\
\hline Information Acces & & \\
\hline Content/ Scope 23 & 233 & 218 \\
\hline Content/ Scope 24 & 226 & 212 \\
\hline Timeliness/ Kecepatan 25 & 233 & 219 \\
\hline Timeliness/ Kecepatan 26 & 234 & 218 \\
\hline
\end{tabular}

Tabel 6 menyajikan nilai kesenjangan antara persepsi dan harapan responden pada tiap item pelayanan perpustakaan.

Tabel 6. Mean Difference Importance dan Performance

\begin{tabular}{|c|c|c|c|c|}
\hline Dimensi & Item & $\begin{array}{c}\text { Mean } \\
\text { Importance } \\
\text { (I) }\end{array}$ & $\begin{array}{c}\text { Mean } \\
\text { Performance } \\
\text { (P) } \\
\end{array}$ & Gap (P-I) \\
\hline \multirow{7}{*}{$\begin{array}{l}\text { Service } \\
\text { Affect }\end{array}$} & Empathy/ Kepedulian 1 & 4,62 & 4,56 & $-0,06$ \\
\hline & Responsivenes 2 & 4,74 & 4,52 & $-0,22$ \\
\hline & Responsivenes 3 & 4,66 & 4,40 & $-0,26$ \\
\hline & Assurance/ Jaminan 4 & 4,64 & 4,52 & $-0,12$ \\
\hline & Assurance/ Jaminan 5 & 4,66 & 4,52 & $-0,14$ \\
\hline & Reliabilitas/ keandalan 6 & 4,62 & 4,46 & $-0,16$ \\
\hline & Reliabilitas/ keandalan 7 & 4,50 & 4,44 & $-0,06$ \\
\hline \multirow{8}{*}{$\begin{array}{l}\text { Library As } \\
\text { Place }\end{array}$} & Tangibles/ bukti fisik 8 & 4,74 & 4,42 & $-0,32$ \\
\hline & Tangibles/ bukti fisik 9 & 4,60 & 4,26 & $-0,34$ \\
\hline & Utilitarian Space 10 & 4,64 & 4,42 & $-0,22$ \\
\hline & Utilitarian Space 11 & 4,58 & 4,12 & $-0,46$ \\
\hline & Symbol 12 & 4,62 & 4,36 & $-0,26$ \\
\hline & Symbol 13 & 4,58 & 4,38 & $-0,20$ \\
\hline & Refuge/ Tempat nyaman 14 & 4,62 & 4,34 & $-0,28$ \\
\hline & Refuge/ Tempat nyaman 15 & 4,70 & 4,44 & $-0,26$ \\
\hline \multirow{2}{*}{$\begin{array}{l}\text { Personal } \\
\text { Control }\end{array}$} & Easy of navigation 16 & 4,68 & 4,54 & $-0,14$ \\
\hline & Easy of navigation 17 & 4,62 & 4,54 & $-0,08$ \\
\hline
\end{tabular}




\begin{tabular}{|l|l|c|c|c|}
\multirow{5}{*}{} & Convenience 18 & 4,58 & 4,20 & $-0,38$ \\
\cline { 2 - 5 } & Convenience 19 & 4,56 & 4,16 & $-0,40$ \\
\cline { 2 - 5 } & Modern Equipment 20 & 4,50 & 3,74 & $-0,76$ \\
\cline { 2 - 5 } & Modern Equipment 21 & 4,74 & 4,46 & $-0,28$ \\
\cline { 2 - 5 } & Self Reliance 22 & 4,70 & 4,48 & $-0,22$ \\
\hline \multirow{4}{*}{\begin{tabular}{l} 
Anformation \\
\cline { 2 - 5 }
\end{tabular}} & Content/Scope 23 & 4,66 & 4,36 & $-0,30$ \\
\cline { 2 - 5 } & Content/Scope 24 & 4,52 & 4,24 & $-0,28$ \\
\cline { 2 - 5 } & Timeliness/ Kecepatan 25 & 4,66 & 4,38 & $-0,28$ \\
\cline { 2 - 5 } & Timeliness/ Kecepatan 26 & 4,68 & 4,36 & $-0,32$ \\
\hline
\end{tabular}

Tabel 6 menunjukkan bahwa keseluruhan item pertanyaan memiliki nilai gap yang negatif. Hal ini berarti pelayanan kepada pemustaka perpustakaan masih berada di bawah harapan responden.

Terdapat 2 nilai gap yang paling besar dalam analisis Tabel 6 , yaitu pada subvariabel library as place pada dimensi utilitarian space (item 11) dengan nilai gap -0,46. Hal ini disebabkan pemustaka mengharapkan ruang perpustakaan memiliki desain yang unik dan nyaman untuk berdiskusi, dan faktanya adalah ruang baca/diskusi bagi pemustaka sangat sempit dan kurang nyaman untuk berdiskusi. Subvariabel personal control pada dimensi modern equipment (item 20) memiliki nilai gap -0,76. Hal ini disebabkan pemustaka menganggap bahwa sarana dan prasarana mesin fotokopi sangat diperlukan oleh pemustaka, dan faktanya adalah ayanan fotokopi tidak disediakan oleh perpustakaan. Sementara itu, 2 nilai gap yang paling kecil ada pada subvariabel service affect pada dimensi reliabilitas (item 7) dengan nilai gap 0,06 yang berarti bahwa kemampuan pustakawan dalam menjawab pertanyaan sudah sesuai dengan harapan pemustaka. Pada subvariabel service affect pada dimensi empathy (item 1) yang memiliki gap 0,06 yang berarti bahwa pustakawan dapat memahami kebutuhan informasi dari pemustaka sesuai dengan apa yang diharapkan oleh pemustaka.

\subsection{Importance Performance Analysis}

Berdasarkan hasil analisis gap diketahui bahwa setiap item bernilai negative, sehingga perlu adanya upaya perbaikan untuk meningkatkan kualitas layanan perpustakaan. Untuk itu, importance-performance analysis (IPA) digunakan sebagai alat bantu untuk menentukan tindakan perbaikan sesuai dengan urutan prioritas perpustakaan. Rumus yang digunakan untuk mengetahui posisi indikator dalam dimensi LibQUAL ${ }^{+\mathrm{TM}}$ dalam mempengaruhi kepuasan pemustaka, ditetapkan sebagai berikut.

Keterangan:

$$
X i=\frac{\Sigma \mathrm{Xi}}{\mathrm{n}} \quad Y i=\frac{\Sigma \mathrm{Yi}}{\mathrm{n}}
$$

$\mathrm{Xi}$ : Skor rata-rata tingkat kinerja layanan perpustakaan

Yi : Skor rata-rata tingkat kepentingan terhadap layanan.

$\mathrm{n}$ : Jumlah responden 
Tabel 7. Importance Performance Matrix

\begin{tabular}{|c|c|c|c|c|c|}
\hline \multirow{2}{*}{ Item } & \multicolumn{2}{|c|}{ Importance } & \multicolumn{2}{c|}{ Performance } & \multirow{2}{*}{ Kuadran } \\
\cline { 2 - 5 } & Total & Rata-Rata & Total & Rata-Rata & \\
\hline 1 & 231 & 4,62 & 228 & 4,56 & IV \\
\hline 2 & 237 & 4,74 & 226 & 4,52 & II \\
\hline 3 & 233 & 4,66 & 220 & 4,4 & I \\
\hline 4 & 232 & 4,64 & 226 & 4,52 & II \\
\hline 5 & 233 & 4,66 & 226 & 4,52 & II \\
\hline 6 & 231 & 4,62 & 223 & 4,46 & IV \\
\hline 7 & 225 & 4,5 & 222 & 4,44 & IV \\
\hline 8 & 237 & 4,74 & 221 & 4,42 & II \\
\hline 9 & 230 & 4,6 & 213 & 4,26 & III \\
\hline 10 & 232 & 4,64 & 221 & 4,42 & II \\
\hline 11 & 229 & 4,58 & 206 & 4,12 & III \\
\hline 12 & 231 & 4,62 & 218 & 4,36 & III \\
\hline 13 & 229 & 4,58 & 219 & 4,38 & III \\
\hline 14 & 231 & 4,62 & 217 & 4,34 & III \\
\hline 15 & 235 & 4,7 & 222 & 4,44 & II \\
\hline 16 & 234 & 4,68 & 227 & 4,54 & II \\
\hline 17 & 231 & 4,62 & 227 & 4,54 & IV \\
\hline 18 & 229 & 4,58 & 210 & 4,2 & III \\
\hline 19 & 228 & 4,56 & 208 & 4,16 & III \\
\hline 20 & 225 & 4,5 & 187 & 3,74 & III \\
\hline 21 & 237 & 4,74 & 223 & 4,46 & II \\
\hline 22 & 235 & 4,7 & 224 & 4,48 & II \\
\hline 23 & 233 & 4,66 & 218 & 4,36 & I \\
\hline 24 & 226 & 4,52 & 212 & 4,24 & III \\
\hline 25 & 233 & 4,66 & 219 & 4,38 & I \\
\hline 26 & 234 & 4,68 & 218 & 4,36 & I \\
\hline & & & & & \\
\hline
\end{tabular}




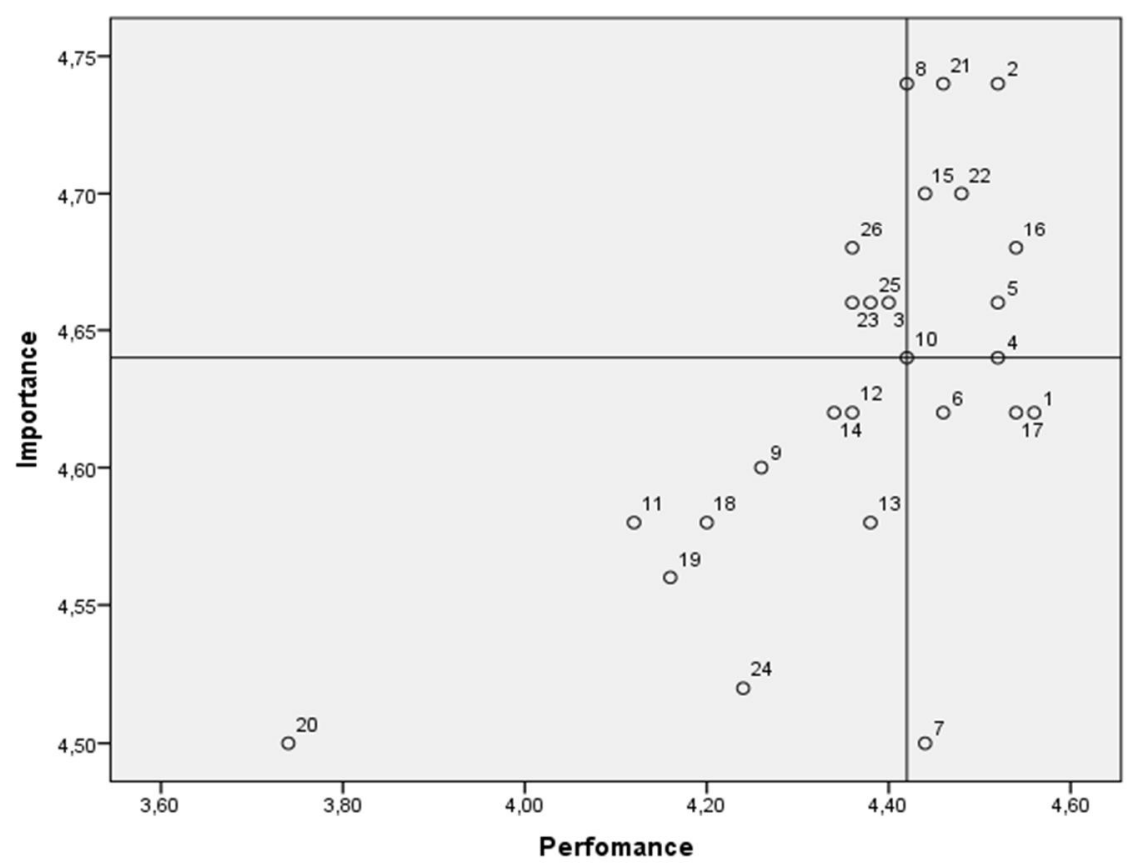

Gambar 2. Diagram importance performance matrix

Diagram Importance-Performance Matrix bertujuan untuk menggambarkan posisi indikator dalam dimensi LibQUAL ${ }^{+\mathrm{TM}}$ yang mempengaruhi kepuasan pemustaka. Gambar di atas menunjukkan posisi indikator yang menempati kuadran I, II, III, dan IV. Dalam Diagram Importance Performance Matrix di atas terdapat 26 titik yang menggambarkan 26 item dalam butir pertanyaan kuesioner penelitian. Diagram Importance-Performance Matrix juga menggambarkan kepuasan pemustaka.

Pada kuadran I ada 4 item, yang mencakup item nomor 3, 23, 25, 26 - menunjukkan bahwa indikator-indikator tersebut dianggap prioritas utama oleh pemustaka dan harus segera diperbaiki oleh perpustakaan (Tabel 8).

Tabel 8. Saran Perbaikan Kualitas Layanan pada Atribut Kuadran I

\begin{tabular}{|c|c|c|}
\hline Item & Pernyataan dan Saran Perbaikan & Dimensi \\
\hline 3 & $\begin{array}{l}\text { Pustakawan selalu tanggap memberikan bantuan dalam mencari } \\
\text { informasi yang saya perlukan. } \\
\text { Saran perbaikan: peningkatan kualitas layanan oleh pustakawan dapat } \\
\text { dilakukan dengan mengikuti pelatihan peningkatan layanan. }\end{array}$ & Responsivenes \\
\hline 23 & $\begin{array}{l}\text { Ketersediaan koleksi sesuai dengan silabus \& kebutuhan saya. } \\
\text { Saran perbaikan: kebutuhan bahan perpustakaan baru dapat } \\
\text { dikonsultasikan dengan peneliti sehingga bahan perpustakaan baru } \\
\text { dapat sejalan dengan bidang ilmu pemustaka. }\end{array}$ & $\begin{array}{l}\text { Content/ } \\
\text { Scope }\end{array}$ \\
\hline 25 & $\begin{array}{l}\text { Kelancaran dalam mengakses berbagai informasi yang saya } \\
\text { butuhkan. } \\
\text { Saran perbaikan: sarana dan prasarana dapat ditingkatkan sesuai } \\
\text { kebutuhan akan penelusuran informasi bagi pemustaka. }\end{array}$ & Timeliness \\
\hline 26 & $\begin{array}{l}\text { Kemudahan akses untuk menemukan informasi yang relevan dan } \\
\text { akurat melalui katalog. } \\
\text { Saran perbaikan: sistem katalog online yang ada sekarang hendaknya } \\
\text { disosialisasikan ke instansi dan perguruan tinggi agar pemustaka } \\
\text { dapat menelusur terlebih dahulu sebelum mencari ke perpustakaan. }\end{array}$ & Timeliness \\
\hline
\end{tabular}


Di kuadran II ada 9 item yang meliputi item nomor 2, 4, 5, 8, 10, 15, 16, 21, 22. -- pada kuadran ini dinilai cukup baik dan mampu untuk dipertahankan. Item yang masuk dalam kuadran II terlihat pada Tabel 9.

Tabel 9. Saran Perbaikan Kualitas Layanan pada Atribut Kuadran II

\begin{tabular}{|c|c|c|}
\hline Item & Pernyataan dan Saran Perbaikan & Dimensi \\
\hline 2 & $\begin{array}{l}\text { Kesediaan pustakawan untuk membantu kesulitan saya di } \\
\text { perpustakaan. } \\
\text { Saran perbaikan: peningkatan kualitas SDM pustakawan dapat } \\
\text { dilakukan dengan mengikuti pelatihan peningkatan layanan. }\end{array}$ & Responsivenes \\
\hline 4 & $\begin{array}{l}\text { Keramahan pustakawan dalam memberikan layanan. } \\
\text { Saran perbaikan: peningkatan kualitas SDM pustakawan dapat } \\
\text { dilakukan dengan mengikuti pelatihan peningkatan layanan. }\end{array}$ & Assurance \\
\hline 5 & $\begin{array}{l}\text { Kesopanan pustakawan dalam memberikan layanan. } \\
\text { Saran perbaikan: peningkatan kualitas SDM pustakawan dapat } \\
\text { dilakukan dengan mengikuti pelatihan peningkatan layanan. }\end{array}$ & Assurance \\
\hline 8 & $\begin{array}{l}\text { Ketersediaan buku di perpustakaan membantu saya menyelesaikan } \\
\text { tugas kuliah. } \\
\text { Saran perbaikan: perpustakaan dapat membuat kotak saran agar dapat } \\
\text { mengetahui kebutuhan apa saja yang diperlukan oleh pemustaka. }\end{array}$ & Tangibles \\
\hline 10 & $\begin{array}{l}\text { Ketenangan ruangan perpustakaan untuk belajar. } \\
\text { Saran perbaikan: kapasitas ruang baca dan kenyamanannya dapat } \\
\text { ditingkatkan sesuai dengan kebutuhan pemustaka. }\end{array}$ & $\begin{array}{l}\text { Utilitarian } \\
\text { Space }\end{array}$ \\
\hline 15 & $\begin{array}{l}\text { Kondisi perpustakaan yang selalu bersih dan dijaga dengan baik, } \\
\text { sehingga kondusif untuk belajar. } \\
\text { Saran perbaikan: kapasitas ruang baca dan kenyamanannya dapat } \\
\text { ditingkatkan sesuai dengan kebutuhan pemustaka. }\end{array}$ & Refuge \\
\hline 16 & $\begin{array}{l}\text { Kemudahan saya dalam melakukan penelusuran informasi di } \\
\text { perpustakaan. } \\
\text { Saran perbaikan: memberi papan petunjuk untuk memundahkan } \\
\text { pemustaka dalam mencari bahan pustaka yang sesuai. }\end{array}$ & $\begin{array}{l}\text { Easy of } \\
\text { navigation }\end{array}$ \\
\hline 21 & $\begin{array}{l}\text { Adanya software otomasi di perpustakaan sebagai alat bantu } \\
\text { penelusuran koleksi. } \\
\text { Saran perbaikan: sistem katalog online yang ada sekarang tetap } \\
\text { dipertahankan sehingga pemustaka dapat lebih mudah ketika mencari } \\
\text { bahan perpustakaan. }\end{array}$ & $\begin{array}{l}\text { Modern } \\
\text { Equipment }\end{array}$ \\
\hline 22 & $\begin{array}{l}\text { Saya dapat melakukan sendiri pencarian informasi di perpustakaan. } \\
\text { Saran perbaikan: sistem katalog online tetap digunakan dan menambah } \\
\text { papan petunjuk di tiap rak koleksi. }\end{array}$ & Self Reliance \\
\hline
\end{tabular}

Pada kuadran III ada 9 item yang terdapat dalam kuadran ini, yaitu item nomor 9, 11, 12 , $13,14,18,19,20,24$. Beberapa item yang terletak pada kuadran ini merupakan atribut yang tidak terlalu membutuhkan perhatian khusus, sebagaimana yang terlihat pada Tabel 10.

Tabel 10. Saran Perbaikan Kualitas Layanan pada Atribut Kuadran III

\begin{tabular}{|c|l|l|}
\hline Item & \multicolumn{1}{|c|}{ Pernyataan dan Saran Perbaikan } & \multicolumn{1}{|c|}{ Dimensi } \\
\hline 9 & $\begin{array}{l}\text { Kondisi gedung maupun peralatan dan perlengkapan yang baik. } \\
\text { Saran perbaikan: menambah peralatan dan perlengkapan yang sesuai } \\
\text { dengan kebutuhan dan dapat menunjang kinerja perpustakaan. }\end{array}$ & Tangibles \\
\hline 11 & $\begin{array}{l}\text { Adanya desain ruangan perpustakaan sebagai tempat diskusi yang } \\
\text { menarik minat pengguna. } \\
\text { Saran perbaikan: kapasitas ruang baca dan kenyamanannya dapat } \\
\text { ditingkatkan sesuai dengan kebutuhan pemustaka }\end{array}$ & $\begin{array}{l}\text { Utilitarian } \\
\text { Space }\end{array}$ \\
\hline
\end{tabular}




\begin{tabular}{|c|c|c|}
\hline 12 & $\begin{array}{l}\text { Perpustakaan dapat memunculkan berbagai inspirasi untuk membaca dan } \\
\text { belajar. } \\
\text { Saran perbaikan: menambah ruang baca tersendiri yang dilengkapi } \\
\text { sarana dan prasarana yang memadai. }\end{array}$ & Symbol \\
\hline 13 & $\begin{array}{l}\text { Perpustakaan terbuka untuk umum dalam belajar/berdiskusi bersama. } \\
\text { Saran perbaikan: menambah ruang baca tersendiri yang dilengkapi } \\
\text { sarana dan prasarana yang memadai. }\end{array}$ & Symbol \\
\hline 14 & $\begin{array}{l}\text { Ketersediaan ruangan perpustakaan yang nyaman untuk belajar. } \\
\text { Saran perbaikan: kapasitas ruang baca dan kenyamanannya dapat } \\
\text { ditingkatkan sesuai dengan kebutuhan pemustaka. }\end{array}$ & Refuge \\
\hline 18 & $\begin{array}{l}\text { Kejelasan petunjuk atau panduan penggunaan fasilitas perpustakaan. } \\
\text { Saran perbaikan: memperbanyak papan petunjuk dapat } \\
\text { mempermudahkan pemustaka dalam mencari bahan perpustakaan yang } \\
\text { sesuai. }\end{array}$ & Convenience \\
\hline 19 & $\begin{array}{l}\text { Kecepatan waktu yang dibutuhkan untuk mendapatkan informasi di } \\
\text { perpustakaan. } \\
\text { Saran perbaikan: peningkatan pengetahuan pustakawan dapat dilakukan } \\
\text { dengan mengikuti pelatihan agar dapat memberi informasi yang cepat } \\
\text { dan tepat pada pemustaka. }\end{array}$ & Convenience \\
\hline 20 & $\begin{array}{l}\text { Tersedianya fasilitas fotokopi yang membantu dan memudahkan saya } \\
\text { memperoleh bahan di perpustakaan. } \\
\text { Saran perbaikan: menambah fasilitas fotokopi agar dapat menunjang } \\
\text { kinerja perpustakaan. }\end{array}$ & $\begin{array}{l}\text { Modern } \\
\text { Equipment }\end{array}$ \\
\hline 24 & $\begin{array}{l}\text { Tersedianya bimbingan pengguna di perpustakaan pada saat dibutuhkan. } \\
\text { Saran perbaikan: peningkatan kualitas layanan oleh pustakawan dapat } \\
\text { dilakukan dengan mengikuti pelatihan peningkatan layanan. }\end{array}$ & Content/Scope \\
\hline
\end{tabular}

Pada kuadran IV, ada 4 item yang mencakup item nomor 1, 6, 7, 17 - pada kuadran ini dianggap tidak terlalu penting sehingga pihak manajemen perlu mengalokasikan sumber daya yang terkait dengan atribut tersebut kepada atribut lain yang mempunyai prioritas penanganan lebih tinggi. Item yang masuk dalam kuadran IV terlihat pada Tabel 11.

Tabel 11. Saran Perbaikan Kualitas Layanan pada Atribut Kuadran IV

\begin{tabular}{|c|l|l|}
\hline Item & \multicolumn{1}{|c|}{ Pernyataan dan Saran Perbaikan } & \multicolumn{1}{|c|}{ Dimensi } \\
\hline 1 & $\begin{array}{l}\text { Pustakawan memahami kebutuhan saya di perpustakaan. } \\
\text { Saran perbaikan: perpustakaan dapat membuat kotak saran agar dapat } \\
\text { mengetahui kebutuhan apa saja yang diperlukan oleh pemustaka }\end{array}$ & Empathy \\
\hline 6 & $\begin{array}{l}\text { Waktu layanan sesuai dengan jam buka/ tutup perpustakaan yang } \\
\text { sudah ditentukan. } \\
\text { Saran perbaikan: jam buka perpustakaan saat ini sesuai dengan jam } \\
\text { kerja karyawan. }\end{array}$ & Reliabilitas \\
\hline 7 & $\begin{array}{l}\text { Kemampuan pustakawan dalam menjawab pertanyaan yang saya } \\
\text { ajukan. } \\
\text { Saran perbaikan: peningkatan pengetahuan pustakawan dapat } \\
\text { dilakukan dengan mengikuti pelatihan yang berkaitan dengan } \\
\text { pengetahuan terbaru. }\end{array}$ & Reliabilitas \\
\hline 17 & $\begin{array}{l}\text { Penataan koleksi perpustakaan memudahkan saya dalam proses temu } \\
\text { kembali informasi. } \\
\text { Saran perbaikan: pusatakawan menata buku lebih spesifik sesuai } \\
\text { kelompok bidang keilmuannya. }\end{array}$ & $\begin{array}{l}\text { Easy of } \\
\text { Navigation }\end{array}$ \\
\hline
\end{tabular}




\subsection{Indeks Kepuasan Pengguna (IKP)}

Berdasarkan perhitungan IKP, tingkat kepuasan pemustaka dapat dilihat pada Tabel 12.

Tabel 12. IKP Perpustakaan Balai Arkeologi Yogyakarta

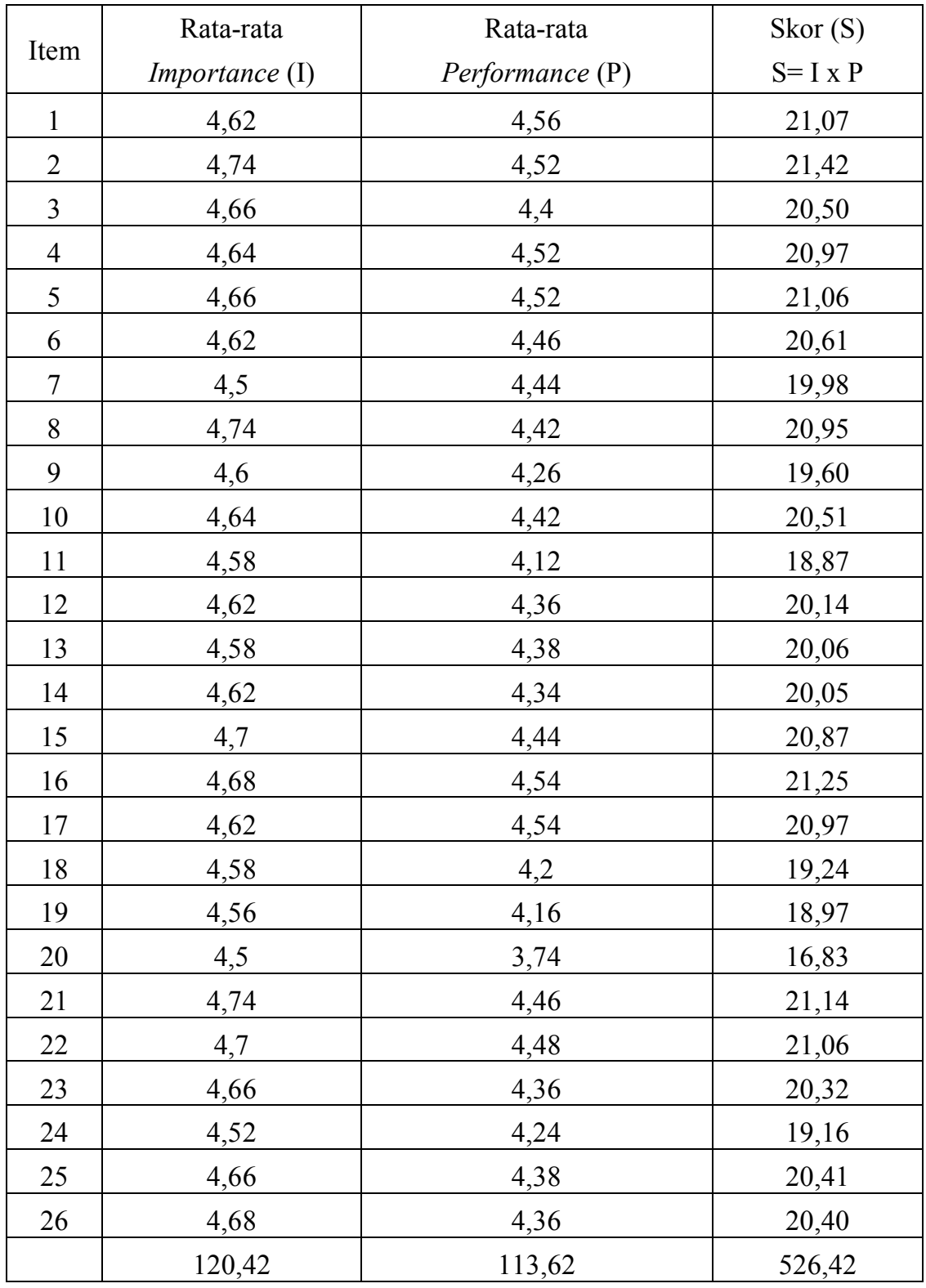

$$
\begin{aligned}
\mathrm{IKP} & =\frac{526,42}{5 \times 120,42} \times 100 \% \\
& =87,43 \%
\end{aligned}
$$

Nilai maksimum IKP adalah 100\%, sehingga nilai IKP 50\% atau lebih rendah - menunjukkan kinerja layanan perpustakaan kurang baik. Nilai IKP di atas 50\% menunjukkan pemustaka merasa puas terhadap kinerja layanan perpustakaan. Nilai IKP di Perpustakaan Balai Arkeologi Yogyakarta menunjukkan angka 87,43 \%, yang menunjukkan bahwa indeks kepuasan pemustaka merasa puas dengan kinerja layanan perpustakaan. 


\section{KESIMPULAN}

Berdasarkan hasil pembahasan di atas dapat disimpulkan bahwa secara keseluruhan tingkat kepuasan pemustaka sebagai responden masih jauh dari harapan. Hal ini terlihat dari nilai gap yang bernilai negatif pada semua pertanyaan kuesioner. Nilai gap terbesar pada subvariabel personal control pada dimensi modern equipment (item 20) yang memiliki Gap 0,76 , yang disebabkan tidak tersedianya mesin fotokopi di perpustakaan. Perbaikan kualitas layanan perpustakaan dapat dilakukan secara bertahap dengan memperhatikan hasil analisis IPA, misalnya pada kuadran I - bagian yang harus segera diperbaiki, perpustakaan perlu mengikutsertakan pustakawannya untuk pelatihan dalam rangka peningkatan kompetensi. Pada item 23 terkait dengan ketersediaan koleksi bagi pemustaka, perlu ada kebijakan pengembangan koleksi yang dikonsultasikan dengan peneliti atau pemustaka sehingga sesuai kebutuhan mereka; menyediakan sarana dan prasarana penelusuran informasi bagi pemustaka; dan melakukan sosialisasi tentang pemanfaatan katalog online bagi pemustaka. Meskipun nilai IKP Perpustakaan Balai Arkeologi Yogyakarta menunjukkan angka 87,43\% (pemustaka merasa puas), lembaga tetap harus meningkatkan kinerja layanan perpustakaan secara kesinambungan. 


\section{DAFTAR PUSTAKA}

Aliza, D.N, \& Ardoni, A. 2017. Penggunaan Metode LibQUAL ${ }^{+T M}$ untuk Mengukur Kualitas Layanan di UPT Perpustakaan UNP. Jurnal Informasi Perpustakaan dan Kearsipan, 6 (1), 210-19.

Bhote, K. R. 1996. Beyond Customer Satisfaction to Customer Loyalty: The Key to Greater Profitability. New York: American Management Association.

Budd, J.M. 2005. The Changing Academic Library: Operations, Cuhures, Environments. America: ACRL Publicationsin Librarianship.

Daniel, C.N. \& Berinyuy, L.P. 2010. Using the SERVQUAL Model to Assess Service Quality and Customer Satisfaction. An Empirical Study of Grocery Stores in Umea. Umeå Universitet.

Fatmawati, E. 2012. Evaluasi Kualitas Layanan Perpustakaan FEB UNDIP Berdasarkan Harapan dan Persepsi Pemustaka dengan Metode LibQUAL ${ }^{+\mathrm{TM}}$." Berkala Informasi dan Perpustakaan, 8(1), 1-18.

Fatmawati, E. 2013. Mata Baru Penelitian Perpustakaan dari Servqual ke LibQUAL ${ }^{+T M}$. Jakarta: Sagung Seto.

Nurkertamanda, D. \& Wirawan, P. 2009. Usulan Konsep Peningkatan Kepuasan Pengguna Perpustakaan dengan Menggunakan Metodologi Libqual ${ }^{\mathrm{TM}}$ dan Quality Function Deployment. Jurnal Teknik Industri, 4(2), 123-36.

Prasetyo, D.N. 2016. Evaluasi Kepuasan Pemustaka terhadap Kualitas Layanan di Perpustakaan Perguruan Tinggi Alma Ata Yogyakarta dengan Metode LibQUAL+TM. Yogyakarta: UIN Sunan Kalijaga.

Prihati, Y. 2011. Model Matematis Pembandingan Tingkat Kepentingan dan Kinerja yang Dirasakan untuk Menentukan Tingkat Kepuasan Pelanggan. Majalah Ilmiah Informatika, 2(2), 1-14.

Saputro, B.I. 2012. Perkembangan dan Peran Perpustakaan Khusus Balai Arkeologi Yogyakarta Sebagai Pendukung Penelitian Arkeologi. PAPUA, 4(1), 73-87.

Sugiyono, S. 2009. Metode Penelitian Kuantitatif Kualitatif dan R\&D. Bandung: Alfabeta.

Supranto, J. 1997. Pengukuran Tingkat Kepuasan Pelanggan. Jakarta: Rineka Cipta.

Suwarno, W. 2016. Organisasi Informasi Perpustakaan. Jakarta: Rajawali Pers.

Thompson, et al. 2012. Layanan Cinta: Perwujudan Layanan Prima Perpustakaan. Jakarta: Sagung Seto.

Wijaya, T. 2011. Manajemen Kualitas Jasa. Jakarta: PT.Indeks.

Woodward, J. 2009. Creating The Customer Driven Academic Library. Am. 